\title{
Acciones y omisiones del Estado costarricense en la expansión piñera: el caso de la Zona Norte-Norte de Costa Rica
}

\author{
Actions and omissions of the Costa Rican State in the pineapple \\ expansion: the case of North Zone of Costa Rica
}

\author{
Alexa Obando Campos \\ Facultad Latinoamericana de Ciencias Sociales \\ Quito, Ecuador \\ ale.obca@gmail.com
}

\begin{abstract}
RESUMEN. La expansión del monocultivo de piña se ha traducido no solo en mayores ingresos económicos para el país, sino también en transformaciones e impactos sociales y ambientales para los cantones productores, como es el caso de Upala, Guatuso y Los Chiles. A partir del enfoque teórico de la antropología del Estado de autores como Abrams (2015), Trouillot (2001), Jessop (2014) y Osorio (2014), se analiza el papel del Estado costarricense a través de sus políticas, prácticas, omisiones y vacíos institucionales. Además, se demuestra cómo a partir de una serie de arreglos territoriales, políticos, económicos y sociales, el Estado se convierte en cómplice de la consolidación de esta industria y la expansión territorial de este cultivo.
\end{abstract}

PALABRAS CLAVE. Agroindustria, piña, monocultivos, Estado, territorio, Costa Rica

\begin{abstract}
The expansion of pineapple monoculture has translated not only into increased economic income for the country, but also into social and environmental transformations and impacts for the producing cantons, as is the case of Upala, Guatuso, and Los Chiles. From the theoretical focus of the anthropology of the State of authors such as Abrams (2014), Trouillot (2001), Jessop (2014) and Osorio (2014), the role of the Costa Rican State is analyzed through its policies, practices, omissions and institutional gaps.
\end{abstract}

Este es un artículo de acceso abierto publicado bajo los términos de la Licencia Creative Commons 4.0 Internacional Atribución-NoComercial-SinDerivadas.

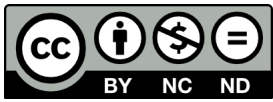


Moreover, it shows how, based on a series of institutional, territorial, political, economic and social arrangements, the State becomes an accomplice in the consolidation of this industry and the territorial expansion of this crop.

KEYWORDS. Agribusiness, pineapple, monocultures, State, territory, Costa Rica

\section{INTRODUCCIÓN}

A partir de los procesos de colonización europea generados en el continente americano, se creó una importante restructuración y orientación de sus economías. De acuerdo con Monzote (2013) esto implicó la instauración de la institución socio-económica más característica de este proceso, la plantación agrícola con destino a la exportación. Los sistemas agrícolas nativos se sustituyeron por un sistema de grandes plantaciones ${ }^{1}$, en la elaboración de productos para el mercado europeo (Wolf, 1982). La producción de caña de azúcar sería la agroindustria dominante en las Antillas (en países como Cuba, Jamaica) y otros cultivos tropicales como el banano, el café, el cacao, el tabaco y el algodón cubrieron grandes extensiones en muchos países de América como Honduras, Costa Rica, Colombia y Ecuador (Monzote, 2013).

Para Wolf (1982) las plantaciones lograron forjar economías de escala, dedicando tantos recursos como les era posible al cultivo de un solo artículo. La instauración de estas plantaciones con sus formas de organización espacial y social, sus nuevas funciones y su control organizacional generaron enclaves ${ }^{2}$ productivos en los diferentes territorios. Sin embargo, los procesos de independencia de las diferentes provincias coloniales convertidas en Estados soberanos no implicaron una ruptura significativa de estos mecanismos de producción espacial, social y económica. En el caso de Centroamérica, a pesar de las diversas restructuraciones políticas, sociales

1 La plantación se puede definir como "una unidad que emplea capital y una gran cantidad de fuerza de trabajo, a la orden de una estrecha supervisión, para producir una cosecha comercial. La fuerza de trabajo opera en grupos que realizan tareas repetitiva y agotadoras bajo la supervisión de capataces que hace cumplir la secuencia y sincronización de tareas" (Wolf, 1982, p. 381).

2 Se puede interpretar como una "isla", con pocas relaciones y vinculaciones con el resto de la economía nacional (Gudynas, 2009). Para Wolf (1985) cuando la plantación se establece en medio de un campo ya habitado, se ve como un "enclave" encajado en un medio extraño. 
y económicas, la región se siguió caracterizando por la implementación de un modelo agroexportador (Vallejo Cerna, 2014). En este contexto, los estados centroamericanos siguieron estableciendo esfuerzos para incentivar el cultivo de materias primas o productos poco procesados, en respuesta a los requerimientos del mercado estadounidense y europeo.

De acuerdo con Vallejo Cerna (2014) el cultivo, la producción y la exportación de productos como el café, el banano y la palma africana, en Centroamérica, creó en sus economías espacios de poder, control social y dinámicas territoriales. Además, como consecuencia, generaron la promoción de diversos escenarios históricos a nivel económico, político, social y cultural. Por lo que, independientemente del impulso de distintos modelos de desarrollo, de políticas o de restructuraciones económicas, Centroamérica ha estado marcada por economías de plantación, enclaves o monoculti$\operatorname{vos}^{3}$ — como hoy en día se les conoce- ligados a la agroindustria.

Es importante tomar en cuenta lo anterior como un contexto previo para entender el caso de la expansión del monocultivo piña y las transformaciones que ha generado en las regiones productoras. Para DeWalt y Stonich (2006) es necesario resaltar que estos casos no pueden ser entendidos ni analizados como procesos aislados de todas las dinámicas que ha atravesado el istmo centroamericano. Dicho esto, se podría decir que actualmente persisten claras interconexiones entre los procesos de colonialismo vividos en Centroamérica y la instauración de estos "nuevos monocultivos" de exportación (Vallejo Cerna, 2014).

Costa Rica no ha sido la excepción, históricamente ha dependido de los monocultivos para desarrollar su economía nacional y se ha convertido en un escenario ideal por sus características ambientales, demográficas, políticas, económicas y sociales. Por eso, la búsqueda de la diversificación productiva por parte del Estado costarricense propició también la creación de nuevos espacios de acumulación, a través de un proceso de ampliación estatal que fue incluyendo progresivamente a las regiones periféricas del país y a la lógica de formación de Estado (León, 2015).

3 Según Gudynas (2013), se entiende como monocultivo a aquellos productos agrícolas que se cultivan de manera intensiva, lo que cubre amplios territorios con altos impactos ambientales y suman enormes volúmenes que son exportados sin procesar o procesamiento mínimo (p. 5). 
Lo anterior ha permitido la persistencia y la consolidación de un modelo de producción agrícola de productos no tradicionales como la piña, el cual es uno de los más exportados del país ${ }^{4}$ (Obando, 2017). En efecto, la expansión de tal cultivo ha generado una serie de impactos ambientales y sociales, como la contaminación de aguas superficiales y subterráneas, el cambio de uso y erosión de suelos, el desvío y sedimentación de ríos, la concentración de la propiedad de la tierra, el desplazamiento de las familias campesinas, la pérdida de la soberanía alimentaria, y el incumplimiento de derechos laborales y posibles daños en la salud por exposición a agroquímicos (Programa Estado de la Nación, 2014, p. 192).

Pese a las distintas denuncias interpuestas no solo por organizaciones de la sociedad civil, sino también por un amplio respaldo investigativo que evidencia tales impactos y consecuencias (Acuña, 2004; Acuña et al., 2018; Aravena, 2005; Avendaño et al., 2014; Aravena y Carazo, 2016; Llaguno et al., 2014; Maglianesi, 2013; Silvetti et al., 2013; Valverde et al., 2016), el rol del Estado costarricense ante esta problemática sigue siendo difuso y poco analizado.

Como resultado de estas dinámicas se han ocasionado fuertes tensiones entre los productores (empresas) y las comunidades afectadas. Ya que, esto ha derivado en disputas entre aquellos actores que abogan por promover la producción, la industria de piña y el crecimiento económico; frente a aquellos que protegen sus recursos naturales y de sustento, y que son los que deben lidiar con los costos ambientales y sociales de estas plantaciones. Además, pareciera que se da una especie de invisibilización de las consecuencias socioambientales de la producción extensiva de la piña en las comunidades, por las ganancias y los réditos en materia económica que genera esta industria en el país (Obando, 2017).

Es importante resaltar que tal problemática alrededor del monocultivo no se genera por la producción de la fruta como tal, sino por el tipo de modelo de producción, es decir, por uno intensivo orientado a la exportación con la introducción de paquetes tecnológicos,

4 La industria de piña costarricense se ha posicionado en los mercados internacionales como líder por su calidad, por sus certificaciones, tratados comerciales, tecnología y el intenso desarrollo de infraestructura y sistemas productivos agroindustriales. Las estadísticas de la Promotora del Comercio Exterior en Costa Rica (Procomer) señalan que este producto ha presentado una evolución positiva en sus exportaciones, donde pasó de generar 816 millones de dólares en el 2013 a 941 millones de dólares en el 2017 (Procomer, 2018). 
y la gran utilización de agroquímicos y mano de obra poco calificada (Acuña, 2006, p. 1). De la misma manera, Gudynas (2013) expresa que este tipo de acciones son características de actividades extractivas, donde se extraen recursos naturales en gran cantidad de volumen o intensidad y están orientadas esencialmente a la exportación de materias primas sin procesar o commodities ${ }^{5}$.

Figura 1. Zona de estudio: cantones de Upala, Guatuso y Los Chiles

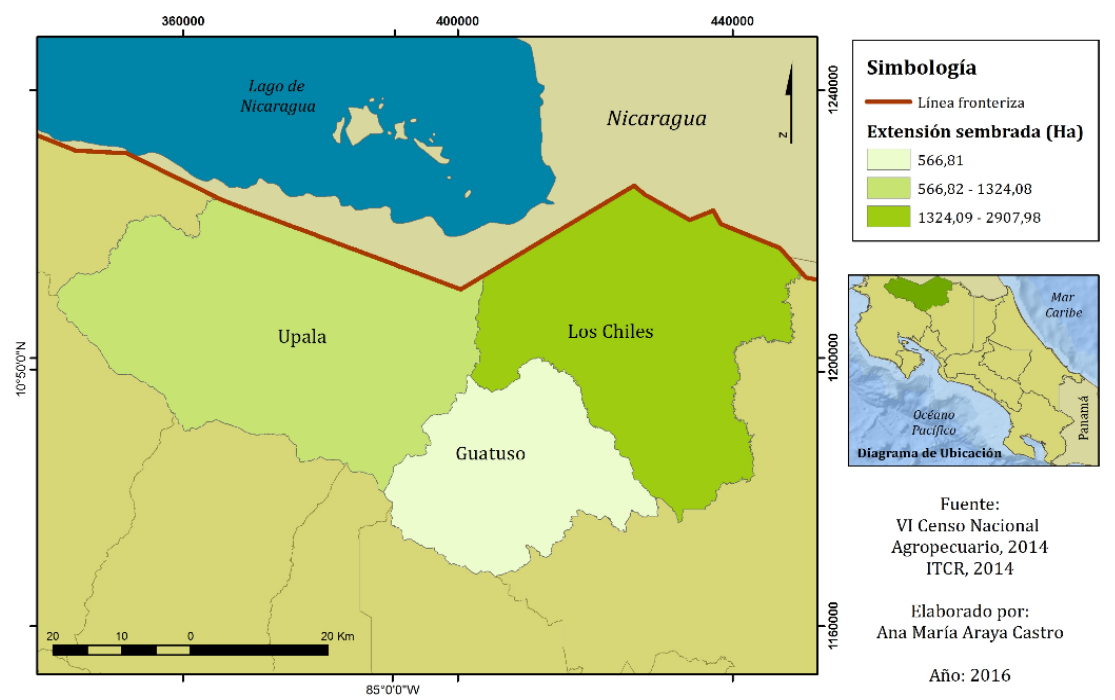

Fuente: Mapa elaborado por Ana María Araya Castro (2016) adaptación bajo la licencia Reconocimiento-Compartir Igual 4.0 Internacional (CC BY-SA 4.0).

De esa manera, el artículo tiene como objetivo poner en discusión el rol del Estado costarricense dentro de la problemática y el conflicto relacionado a la expansión del monocultivo de piña en los cantones de Upala, Guatuso y Los Chiles, de la provincia de Alajuela, que se denomina la Zona Norte-Norte (ZNN) (ver Figura 1). Esto para evidenciar cómo el Estado a partir de una intervención previa de los territorios, generó las condiciones idóneas para facilitar y promover el desarrollo de la agroindustria. Y al mismo tiempo, es quien profundiza y potencia la problemática asociada, por sus omi-

5 Se refiere a bienes que son considerados homogéneos independientemente de su origen, donde no existe una diferenciación entre sus variedades, que incluso pueden estar estandarizados, y que son comercializados en grandes volúmenes (Gudynas, 2013, p. 6) 
siones y la falta de mecanismos de regulación y fiscalización en los sistemas de producción de piña (Obando, 2017).

Así también, por un lado, esta investigación intenta acercarse desde enfoque teórico de la antropología del Estado ${ }^{6}$, retoma autores como Phillip Abrams (2015)7, Michel Rolph Trouillot (2001b) Jaime Osorio (2014) y Bob Jessop (2014); los cuales consideran al Estado desde un aspecto dual, es decir, como un asunto material - $\mathrm{O}$ aparato estatal-, pero también como una ilusión, una ideología o una representación distorsionada de la dominación política y económica (Schavelzon, 2010). Por esa razón, los autores mencionados consideran que el Estado no debe analizarse como una entidad unitaria, coherente o neutral, pues tal perspectiva no permite entender las dinámicas sociales tan complejas en las que se desarrolla el Estado y no tomaría en cuenta la interdependencia que hay entre este y la sociedad.

Por otra parte, los hallazgos y reflexiones planteadas en este artículo son el resultado de la tesis para optar por el grado de licenciatura en Ciencias Políticas de la Universidad de Costa Rica, llamada "El Estado detrás de la piña: El conflicto socioambiental del monocultivo de piña en los cantones de Upala, Guatuso y Los Chiles (2000-2015)", así como de investigaciones paralelas realizadas con un equipo investigación. Este trabajo se llevó a cabo entre el año 2016 y 2017 y se empleó un diseño metodológico cualitativo. Entre las técnicas de recolección de datos utilizadas, se realizó una amplia revisión bibliográfica de fuentes primarias y secundarias y se aplicaron alrededor de 15 entrevistas semiestructuradas a diferentes actores implicados. Asimismo, se visitó la zona de estudio y se realizó observación participante en algunas comunidades de la zona ${ }^{8}$.

6 Para Hevia de la Jara (2009) se puede entender como un campo en proceso de consolidación en la antropología política, el cual genera un análisis relacional o interactivo entre la sociedad y Estado, y parte del entendimiento de que es necesario comprender las diversas agencias del Estado a partir de relaciones que desarrolla con actores sociales variados.

7 Publicación traducida al español del artículo original de Phillip Abrams (1988). 8 Se trabajó con miembros de comunidades de Pavón y Caño Negro de Los Chiles, de Canalete de Upala y con la comunidad indígena Maleku ubicada en San Rafael de Guatuso y se participó en actividades realizadas por la organización CLANN (Coordinación Lucha Ambiental Norte Norte), la cual reunía personas de los tres cantones en estudio. 


\section{ALGUNAS APROXIMACIONES TEÓRICAS PARA ANALIZAR Y PROBLEMATIZAR EL ESTADO}

Es evidente que la categoría y el concepto de Estado ha sido abordado de diversas maneras y disciplinas como objeto de estudio, sin que haya un consenso sobre una teoría o perspectiva teórica que logre capturarlo en su totalidad y explicar sus dinámicas estructurales, políticas y territoriales (Obando, 2017). Para Jessop, en el lenguaje cotidiano se tiende a representar al Estado como un sujeto - el Estado hace, o debe hacer esto o aquello-. En otras ocasiones, se refiere al Estado como objeto o instrumento, concibiendo que cierta clase económica, estrato social o partido político usa el Estado para perseguir sus proyectos e intereses (Jessop, 2014, p. 21). No obstante, el Estado no es un sujeto ni un objeto.

Por lo tanto, ¿qué es el Estado? ¿cómo llegan los actores sociales a actuar como si el Estado fuese un sujeto real o un simple instrumento? Resulta difícil encontrar una respuesta definitiva a tales interrogantes y que sea coherente con todas las perspectivas teóricas acerca del Estado, debido a que éste cambia de forma y de apariencia en función de las actividades que desarrolla, de las escalas en las que opera, de las fuerzas políticas que actúan en él y de las circunstancias (Jessop, 2014, p. 21).

Desde la antropología del Estado, Schavelzon (2010) distingue una oscilación entre dos puntos de vista que atraviesan muchas investigaciones del estudio del Estado.

Para algunos el Estado es una entidad o una racionalidad omnipresente y diseminada por todo lugar, incluso más allá de las instituciones del gobierno. Para otros, el Estado es una ficción que debemos descartar del análisis, una construcción ideologizada y, por tanto, el Estado no es un concepto que sirva siquiera para pensar instituciones del gobierno (Schavelzon, 2010, p. 88).

Para el autor, a pesar de que la antropología del Estado sigue siendo diversa y poco unificada, es al mismo tiempo establecida. Esto obedece a que más allá de una disciplina que está incursionando en "campo ajeno" o de estudios afines a la sociología, la historia o las ciencias políticas, muestra una especificidad para abordar el Estado y ayuda a complementar otras perspectivas. De manera que, esta área se posiciona para encontrar la precariedad y violencia en el propio Estado, que avanza proponiendo "civilizar" y controlar 
aquellos territorios donde la unificación y la representación no son aún dominantes (Schavelzon, 2010)

Justamente, para Abrams la idea de dejar de lado el Estado es necesaria, con el fin de ocuparse de las relaciones que éste oculta. Por eso, en su propuesta el autor concibe al Estado ya no solo en su dimensión material, sino en su dimensión como idea, es decir, como proyecto ideológico y como ejercicio permanente de búsqueda de legitimidad: "Se busca legitimar un conjunto de hechos que deberían ser considerados verdaderamente inaceptables: podríamos decir que el Estado es la falsa representación colectiva característica de las sociedades capitalistas" (2015, p. 52).

Al igual que Abrams (2015), autores como Osorio (2014) coinciden en plantear que el Estado sintetiza costumbres, valores compartidos y traza un rumbo con metas comunes para los miembros de una sociedad. Esto con el objetivo de presentarse como una comunidad que dice buscar el bien común y el bienestar de todos. De esta manera, condensa y se desliga de las relaciones e intereses sociales de las clases dominantes ligadas al capital y presentarse como un Estado de todos y una comunidad de iguales.

Asimismo, Abrams (2015) utiliza una metáfora para tratar de entender al Estado, cuando lo presenta como una "máscara ahistórica de legitimidad ilusoria", el cual se las arregla para negar la existencia de conflictos y conexiones, y sea compatible con la autonomía reclamada y la integración del Estado (Abrams, 2015, p. 55). Por consiguiente, esta máscara del Estado, es una especie de triunfo de ocultamiento, en el sentido que oculta la historia y la relaciones reales de sujeción y se presenta de manera distorsionada de lo que en realidad es: una síntesis relacional de poder y de dominio de clases (Osorio, 2014, p. 26).

De acuerdo con Abrams (2015), el Estado es una máscara que debe ser puesta entre paréntesis para acceder a la práctica política. Por eso, propone separar la "idea de Estado" (como es imaginado concretamente y cómo las ideas sobre él legitiman la dominación política) del "sistema de Estado" (el aparato institucional y sus prácticas). Aunque el primero es importante, el segundo debe ser un objeto central para cuestionar la imagen del Estado como una entidad dada y entender las relaciones y las formas de subordinación social (como se citó en Arias, 2016; Schavelzon, 2010).

Desde esta perspectiva, Osorio (2014) sigue la línea de Abrams 
al entender al Estado como la condensación de relaciones sociales de dominio específicas, que se cristalizan en poder político, concibiéndolo desde dos dimensiones. La primera, su cara "invisible" (ya que no se manifiesta de manera inmediata), la cual es el centro del poder político, en tanto tiene la capacidad de llevar adelante proyectos de determinados intereses sociales. Y la segunda, su cara "visible", que hace referencia a un conjunto de instituciones, leyes y normas, que junto al personal del Estado conforman el aparato estatal (o aparato del Estado que es su condensación material) (Osorio, 2014, pp. 183-184).

El aparato estatal, en ese sentido, es vital para el poder político, ya que todo lo que hace el Estado lo realiza a través del mismo y este funciona como una especie de filtro, al determinar la modalidad de intervenciones económicas e ideológicas del Estado. Por eso, Osorio (2014) considera que no hay que perder de vista todas las labores administrativas, pues están atravesadas por el aparato del Estado, aunque estas tiendan a percibirse como tareas "neutrales" desde el punto de vista social. Por su parte, Jessop (2014) define al aparato estatal como un conjunto distintivo de instituciones y organizaciones cuya función socialmente aceptada consiste en definir y hacer cumplir las decisiones colectivamente vinculantes en una población en nombre del "interés común" o "voluntad general" (Jessop, 2014, p. 25).

Es así que las reflexiones de Abrams (1988) acerca del Estado abrieron líneas de investigación como la de Trouillot (2001) el cual considera que el Estado va más allá de las instituciones gubernamentales o nacionales, para centrarse en los múltiples sitios en los que los procesos y prácticas estatales son reconocibles a través de sus efectos, es decir, apunta al estudio de los efectos que produce el Estado. Dentro de su propuesta, para este autor el Estado aparece como un campo abierto con múltiples límites, sin fijación institucional, lo que significa que debe conceptualizarse en más de un nivel.

Aunque está vinculado a una serie de aparatos, no todos los cuales pueden ser gubernamentales, el Estado no es un aparato sino un conjunto de procesos. No está necesariamente obligado por ninguna institución, ni ninguna institución puede encapsularlo por completo. En ese nivel, su materialidad reside mucho menos en las instituciones que en la reelaboración de procesos y relaciones de poder para crear nuevos espacios para el despliegue del poder (Trouillot, 2001a, p. 127). 
Por tanto, conceptualizar el Estado, no como algo dado, sino como procesos y relaciones permite entender las luchas históricas y políticas entre distintos actores por el dominio y la sujeción política, a la vez que, reconocer al Estado de la manera dual — como lo presenta Abrams (1988) y posteriormente autores como Trouillot (2001), Jessop (2014) y Osorio (2014) — consiente, en el marco de esta investigación, considerarlo en su desagregación en diferentes escalas, que no operan bajo las mismas lógicas. También, permite considerarlo en su concreción, en sus encarnaciones y en sus funcionarios; al igual que analizar las múltiples y entramadas relaciones de poder en distintos niveles e instancias, así como los complejos juegos de lecturas y reinterpretaciones, silencios, acomodos, omisiones, invenciones y acatamientos entre diversos actores (Barragán y Wanderley, 2009).

\section{EL ESTADO Y LA INCLUSIÓN DE LA ZONA NORTE DE COSTA RICA}

La Zona Norte (ZN) de Costa Rica se caracteriza por haber sido conformada por procesos migratorios e inmigratorios de poblaciones campesinas e indígenas provenientes del interior del país, como el Valle Central, la Región Chorotega y otras comunidades aledañas provenientes de Costa Rica y Nicaragua (Acuña y Valverde, 2011, p.7). Sin embargo, la construcción de la nación costarricense ha tenido una clara diferenciación entre el Valle Central y las periferias. Esto se debe a que el imaginario nacional se fundó en la visión blanca, homogénea y pacífica, vinculada directamente con el mito de democracia agraria, supuestamente propia de la producción cafetalera del Valle Central (León, 2015, p.35).

Pero, es hasta el agotamiento de la frontera agrícola, aproximadamente a finales de la década de los setenta, y del proceso de ampliación estatal que, progresivamente las regiones periféricas fueron incluidas dentro de la lógica de formación del Estado - específicamente en la ZN-. Esta situación coincide con la supuesta necesidad de generar un proceso de regionalización nacional. Los motivos primordiales para la expansión estatal fueron principalmente económicos y estaban relacionados con la estructura agro-exportadora tradicional (Obando, 2017).

De esta forma, el Estado costarricense se empieza a presentar como un promotor activo del proceso de colonización de la región, 
por medio de instituciones como el Instituto de Tierras y Colonización (ITCO) —actual Instituto Desarrollo Rural (INDER) - , el Consejo Nacional de Producción (CNP) y la Caja Costarricense del Seguro Social (CCSS). "La década de los setenta marca el inicio del "desenclave de la zona norte costarricense"" (León, 2015, p.40), ya que para ese momento se podía observar una cierta consolidación del proceso de colonización de la $\mathrm{ZN}$, con la existencia de ciudades como Tilarán, Ciudad Quesada, Los Chiles y Upala.

En términos generales, el proceso de articulación de la región con el Valle Central se caracterizó por la destrucción del sistema de comunicación fluvial que predominaba históricamente en la ZN, y que la había acercado mucho más a Nicaragua que al resto del país, debido a la falta de rutas permanentes que conectaran esta zona con el Valle Central. De acuerdo con León (2015) todo este proceso mostró un claro funcionamiento periférico-dependiente, caracterizado por una lógica extractiva y de "válvula de escape" a la creciente conflictividad rural a nivel nacional y causado por el agotamiento de la frontera agrícola, la que generaba la necesidad de crear nuevos espacios de acumulación.

Sin embargo, la crisis financiera que atravesó Costa Rica a finales de los setenta y principios de los ochenta implicó la ejecución de un conjunto de transformaciones estructurales ${ }^{9}$, así como el impulso de un nuevo modelo de Promoción de Exportaciones ${ }^{10}$ como forma de estabilizar y reactivar la economía, saldando las deudas contraídas (Arias y Muñoz, 2007, como se citó en Avendaño et al., 2014, p.44). Tal estrategia ${ }^{11}$ implicó una profundización de los patrones

9 El ajuste fue aplicado por medio de tres mecanismos generales: en primera instancia, la condicionalidad cruzada de los organismos financieros internacionales, luego la inyección de ayuda externa por parte de Estados Unidos, por medio de su agencia de Cooperación y por último, la entrada en vigencia de la iniciativa para la Cuenca del Caribe (ICC) de Estados Unidos en 1984 (León, 2015, p. 52).

10 Esta nueva estrategia de desarrollo se basa en cinco pilares fundamentales (1) apertura al exterior o liberalización comercial , (2) reforma del Estado, (3) privatización y apertura de mercados, (4) mercado laboral o flexibilización y (5) apertura, financiación y atracción de inversión extranjera directa (León, 2015, p. 56).

11 Para solventar los problemas causados por la crisis, se inició en 1982 un programa de estabilización de la economía con el FMI, que se conocen como los Programas de Ajuste Estructural (PAE). Lo que dio inicio a un proceso de reformas financieras y fiscales para la estabilización de la economía y la creación de condiciones para su reactivación (Fernández y Granados, 2002, como se citó en Castillo, 2006, p. 18). 
capitalistas que se estaban imponiendo desde las potencias mundiales, especialmente al impulsar y posicionar al sector privado y apostar por la estimulación de nuevos bienes agrícolas que fueran cultivados a gran escala o bajo el método de monocultivos (Casti1lo, 2006).

Todo ese proceso se enmarcó dentro de una lógica neoliberal con claros fines de lucro, al elevar las ganancias y facilitar la subvaloración de las necesidades internas (Avendaño et al., 2014, p. 44). Esto no sólo vino a impactar la esfera productiva, sino también a modificar el paisaje y las relaciones sociales de los espacios rurales, como los de la ZN (Obando, 2017). Pese a todos los esfuerzos por acercar la $\mathrm{ZN}$ a las lógicas del Estado, durante este periodo, la frontera aún se mostraba fuera de su control. Por lo tanto, la estrategia para este espacio fronterizo era convertirlo en una "frontera viva" (Granados y Quesada, 1986), es decir, una región integrada política, económica y culturalmente al Estado costarricense (León, 2015, p. 61).

Como respuesta, entra en vigencia el Proyecto Integral de la Zona Norte (PIZN) que establecía la construcción de un sistema de caminos rurales que interconectaban la región a partir de la carretera Interamericana y otras vías centrales. Tal proyecto ayudaría a interconectar los diferentes asentamientos campesinos y el mejoramiento de los servicios de salud, educación e infraestructura (Granados y Quesada, 1986). Según el PIZN, este proceso permitiría la confluencia entre intereses nacionales y extranjeros (León, 2015, p.61).

Al presentar las condiciones óptimas para el desarrollo de nuevos productos agrícolas y con el papel cada vez más relevante de la inversión extranjera directa, en la ZN se empiezan a promover e introducir los productos no tradicionales para la exportación como la piña, la naranja, las plantas ornamentales, la yuca, la sandía, el melón, entre otros. En esta nueva estructura productiva, se va a dar la instalación de empresas transnacionales en diversas regiones del país, así como la intervención de capital privado y extranjero.

Lo anterior coincide, justamente, con el inicio de la producción de piña para la exportación, la cual se dio a mediados de la década de los ochenta con la introducción de paquetes tecnológicos (que mejoran su calidad y dulzor) por parte de la compañía transnacional Pineapple Development Company (PINDECO), en el pacífico sur del país. A pesar de que, desde la época colonial, el cultivo ya se 
daba tradicionalmente en las provincias de Alajuela y Puntarenas (Aravena, 2005).

La llegada de empresas como PINDECO a la Zona Sur deriva de arreglos institucionales y de la creación de entidades como la Coalición Costarricense de Iniciativas de Desarrollo (CINDE) ${ }^{12}$ y el Centro para la Promoción de las Exportaciones y las Inversiones, $(\mathrm{CENPRO})^{13}$ —institución que autoriza la entrada de las distintas empresas en alguno de los sistemas de incentivos a la exportación disponibles en Costa Rica- (Acuña et al., 2018). Durante esta épo$\mathrm{ca}$, el sector agrícola adquiere un protagonismo indiscutible en la restructuración de la economía, tanto en materia de exportaciones e importaciones, como en el esfuerzo por modernizar las unidades productivas rurales para mejorar el manejo de los nuevos cultivos buscando calidad y procesamiento, y así, competir en el mercado internacional.

Se puede identificar un antes referido a la etapa de producción piñera que se desarrolla en tiempos de la colonia de forma tradicional, y un después, que vincula la entrada de nuevos actores empresariales y el cambio en los objetivos de la producción, ya que se orienta a la exportación (Obando, 2017, p.79).

Para Acuña (2004) el punto de giro debe ser ubicado cuando PINDECO inicia operaciones en el país y la actividad adquiere características de monocultivo de alta intensidad y demanda tecnológica. Además, introduce nuevas variedades del producto y estimula la operación de la actividad en otras zonas, como la ZN. No obstante, es hasta finales de los noventa y principios del nuevo milenio que se introduce una nueva variedad de piña, produciendo toda una revolución en el mercado mundial. Es la variedad conocida con el nombre científico de $\mathrm{MD} 2{ }^{14}$ o Sweet Golden la que cambiaría tanto el

12 Organización que brinda apoyo a inversionistas extranjeros en su establecimiento de negocios en el país

13 Creado como ente regulador de los sistemas de incentivos fiscales desarrollados por el gobierno costarricense para atraer nueva inversión en sectores de exportación. Dado que su orientación es el aumento de las exportaciones nacionales, no lleva a cabo controles acerca de los métodos de producción utilizados y los potenciales efectos ambientales que éstos puedan tener. Su función se limita a asegurar que las empresas cumplan con los requerimientos administrativos establecido en el sistema de incentivos (Berrocal et al., 1997, p. 19).

14 Se caracteriza por una forma más asimétrica y uniforme, posee un muy atractivo color amarillo externamente y en el interior se grado de azúcares es más alto y 
mercado nacional e como el internacional, así como la mentalidad de esta actividad productiva (Acuña 2004, p.15).

A grandes rasgos, esta etapa estuvo marcada por un aumento significativo de la presencia del Estado en la región, con el fin de controlar e influir en los procesos económicos, políticos y sociales, que respondieran a las nuevas reformas de ajuste estructural que fueron impulsadas desde las élites y el Gobierno Central de forma vertical (Obando, 2017). Este proceso estuvo marcado por altos niveles de descoordinación entre las diferentes instituciones públicas (León, 2015, p.67) y la región siguió desempeñando un papel periférico y fundamentalmente oferente de materias primas. Además, la estrategia de acercar cada vez más a la $\mathrm{ZN}$ generó una afectación importante en las dinámicas transfronterizas con los territorios nicaragüenses y al mismo tiempo a lo interno de cantones de Upala, Guatuso y Los Chiles (Obando, 2017).

\section{LA PIÑA LLEGÓ PARA QUEDARSE: EL ESTADO COMO PROMOTOR DE LA AGROINDUSTRIA EN LOS CANTONES DE UPALA, GUATUSO Y LOS CHILES}

La puesta en práctica de políticas neoliberales que se impulsaron en Centroamérica en la década de los ochenta, causaron un fuerte deterioro de los sistemas y estructuras productivas tradicionales, que afectó directamente a las regiones periféricas de los distintos países (Rodríguez, 2008). Todo el proceso que traía el nuevo modelo de apertura comercial contribuyó a transformar la estructura productiva nacional, la cual empezaba a impulsar la introducción cada vez mayor de productos no tradicionales para la exportación. En ese sentido, el desarrollo de dichos productos en la ZNN afectó principalmente a las economías campesinas (pequeña y mediana) dedicadas a la producción agropecuaria.

El cultivo de granos básicos en esta zona era "en una forma de vida", sencilla, rudimentaria, con pocos agroquímicos, con una labranza no muy sofisticada que producía y mantenía a nuestras comunidades. Sin embargo, la piña llega a desarticular el sistema de producción natural del cantón (de Upala) por lo que dejó sin opción a muchos agricultores, ya que empezamos a experimentar el recorte en los sistemas de apoyo, como el otorgamiento de semillas

porta cinco veces más ácido ascórbico o vitamina C (Acuña 2004, p.15) 
y de asistencia técnica (A1, miembro de la comunidad de Canalete, comunicación personal, 13 de julio de 2016) ${ }^{15}$.

Figura 2. Costa Rica: Área sembrada en hectáreas de actividades agrícolas tradicionales y no tradicionales en la provincia de Alajuela, 1984,2014

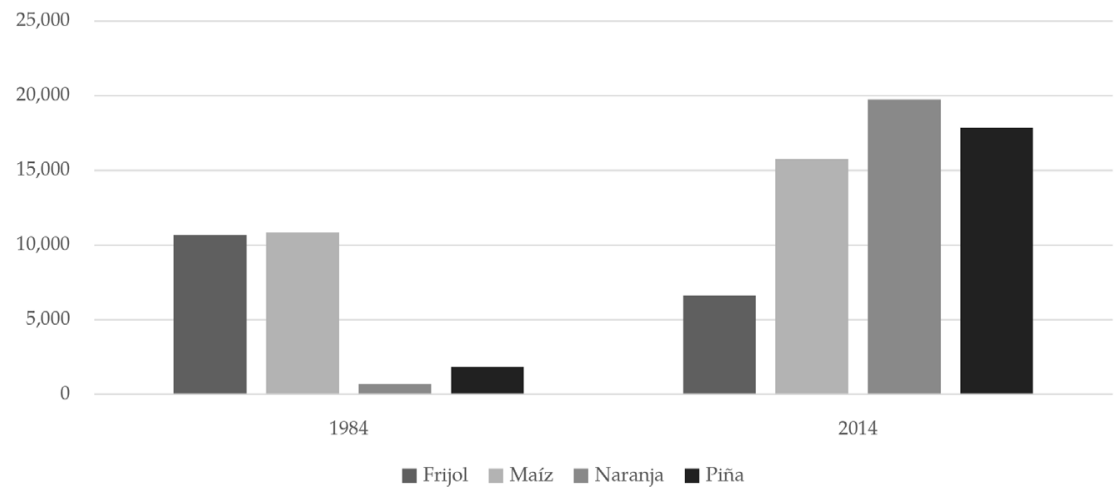

Nota. Elaboración propia, con base en Censo Nacional Agropecuario de 1984 y 2014.

La implementación de nuevos cultivos en la zona, desplazó a otros tradicionales como el arroz, el maíz y los frijoles, orientados al autoconsumo o al mercado nacional. Por lo tanto, ese crecimiento significativo de las actividades productivas no tradicionales y la acentuada disminución de granos básicos, modificó el panorama rural de estos espacios. Esto puede evidenciarse en los procesos de restructuración socioeconómica que experimentaron algunas regiones; así como cambios en el paisaje (Avendaño et al., 2014, p. 47).

La Figura 2 como en cuestión de 30 años, los productos no tradicionales, como la piña y la naranja, pasan a ser dominantes en la ZN a pesar de su tardía introducción en la estructura agropecuaria nacional. Esto ha generado una caída paulatina de la producción, extensión en hectáreas y exportación de granos básicos, ya que se apostó a una estrategia de ventajas competitivas (Obando, 2017).

Algunos pobladores de las comunidades expresan que perciben esa disminución en la producción de granos básicos de la región. "Primero llegó la naranja y luego junto con la piña, vinieron a des-

15 Se estableció una codificación para cada persona entrevistada con el fin de proteger su identidad. 
aparecer lo que eran 13 mil o 15 mil hectáreas de frijoles y también de maíz" (A2, miembro de la comunidad de Pavón de Los Chiles, comunicación personal, 27 de julio de 2016).

Aquí se siguen cultivando frijol y maíz, pero a pequeña escala y se destaca la ganadería de leche. Nuevamente se está produciendo cacao, no obstante, uno no se siente el apoyo decido por parte del Estado, para apoyar otras alternativas agrícolas, ya que se percibe que el Gobierno quiere hacer la mínima inversión. Está interesado en que vengan empresas con capital extranjero a invertir en piña y traer un desarrollo que aparentemente beneficia al cantón, pero en realidad beneficia a la compañía y daña el ambiente y la salud de nosotros (A1, miembro de la comunidad de Canalete, comunicación personal, 13 de julio de 2016).

El crecimiento, cada vez mayor de la producción de piña, fue impulsado por el establecimiento, de incentivos a actividades no tradicionales, a finales de la década de los ochenta y durante la década de los noventa. La estructura económica costarricense se combinó entonces con un conjunto de condiciones del mercado internacional y acciones orientadas a la dinamización del sector piñero, como la promulgación de leyes, el establecimiento de incentivos productivos y la creación de instituciones (Ver Figura 3) (Acuña, 2004, p.9).

Figura 3. Línea del tiempo de los principales incentivos estatales a la producción piñera

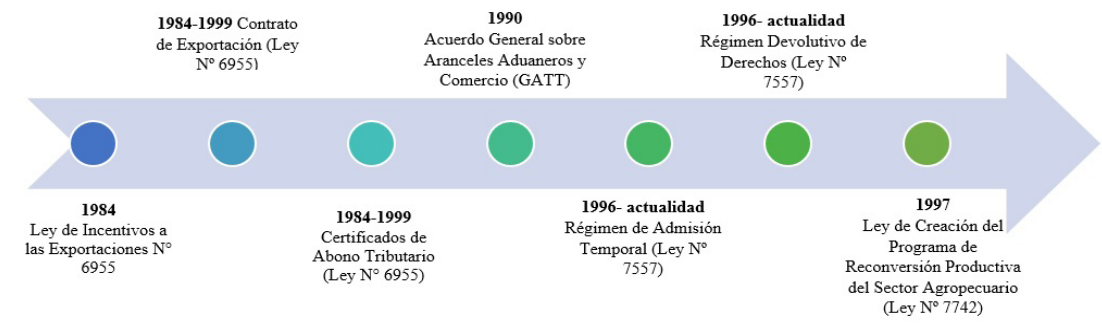

Fuente: Elaboración propia, con base en Quijandra et al. (1997, p.13) y Alonso (2013, p. 2). 
Ahora bien, Colburn y Raventós (1998) explican que algunos incentivos comprendían la exención del impuesto corporativo y de los aranceles que se destinarían al mercado extra regional. Además, se creó el Consejo Nacional de Inversiones (CNI) para aprobar los programas y los contratos de exportación, otorgar certificados de abono tributario y otros incentivos. Sin embargo, Costa Rica no tuvo las experiencias previas de planificación, ya que esta actividad inició de manera acelerada ante la abundante demanda del mercado internacional (Hernández et al., 2015). La estimulación de su producción por medio de arreglos institucionales, llámese, créditos, programas, políticas, asistencia técnica y financiera, no se contrarrestó con mecanismos idóneos de fiscalización, monitoreo y seguimiento para la actividad, por lo que actualmente opera con muchos vacíos legales e institucionales (Obando, 2017).

Para Valverde, Porras y Jiménez la conjugación de todos estos factores generó un proceso de reconversión agrícola en la ZN, donde se pasó de la producción de granos básicos a una producción de commodities (Valverde et al., 2016, p. 5). A pesar de que esta zona logró transformar su dinámica productiva para adecuar su desarrollo a las nuevas condiciones del contexto nacional e internacional, este desarrollo alcanzado no se ha traducido en beneficios semejantes para las comunidades de la zona (Barrientos y Chaves, 2008, pp.24-25). Todo se enmarca en un proceso de reducción de las funciones del Estado y de recorte a políticas agrarias dirigidas a incentivar la producción tradicional, que constituía el soporte de pequeños y medianos agricultores (Obando, 2017).

Específicamente, en el caso de los cantones de Upala, Guatuso y Los Chiles, se da una marginalización y destrucción de cadenas productivas locales (frijoles y maíz), y se sustituye por encadenamientos mundiales, donde se forman redes comerciales que no respetan fronteras ni la especificidades de las economías pequeñas (Mora, 2005 en Avendaño et al., 2014, p.53). Los diferentes incentivos, créditos y políticas que propiciaron las instituciones estales fueron acaparados por aquellos productores con capacidades adquisitivas que podían ofrecer mejores garantías de pago, por lo que estuvo altamente concentrado en las empresas más grandes de la zona (Obando, 2017).

Los pequeños y medianos productores en este contexto, quedaron excluidos del proceso de modernización del sector agropecuario, al no contar con las posibilidades de desarrollarse frente a las 
grandes industrias (Obando, 2017). De acuerdo con algunas entrevistas realizadas,

Los pequeños productores que intentaron desarrollarse en la industria piñera con cinco, seis o diez hectáreas no pudieron. Porque fueron absorbidos por lo más grandes, ya que la cantidad que ellos producían no alcanzaba el mínimo para sostener una empresa, por lo que quebraron y quedaron con deudas. Perdieron sus propiedades y otros tuvieron que recurrir a préstamos extra para cancelar sus deudas. En el cultivo de piña sobrevive la empresa grande (A1, miembro de la comunidad de Canalete, comunicación personal, 13 de julio de 2016).

Los altos costos operativos, el limitado acceso a las certificaciones ${ }^{16}$ de exportación, los paquetes tecnológicos e insumos técnicos para cumplir todo el proceso de la cadena productiva no fueron ni son accesibles para todos los productores. A medida que avanza el proceso productivo, la cadena se vuelve excluyente y selectiva. Aunque se estimula la entrada de pequeños productores, una vez adentro, no se garantiza su permanencia en la cadena y se transfieren los riesgos de producción a los más pequeños, provocando que se forme una especie de embudo (Obando, 2017). Ante este panorama, algunos pequeños y medianos productores optaron por asociarse para poder resistir estas condiciones que los ponen en desventaja frente a las grandes empresas.

Nosotros desde la Asociación ofrecemos acompañamiento y asistencia técnica en todo el proceso de siembra y cosecha, para que luego el productor se lo vender a Agronorte y así asegurarle siempre un mercado al pequeño productor. Pero este mercado es duro, ahorita tenemos 50 productores asociados con tres, cinco, diez hectáreas. Antes había muchas otras asociaciones como la de nosotros, pero es difícil mantenerse. Nosotros somos ya una de las pocas que quedan (A3, funcionaria de Asociación Agronorte,

16 Las certificadoras son agencias privadas independientes que realizan auditorías e inspecciones de campo generando informes que establecen la veracidad de las buenas prácticas y la sostenibilidad de sus procesos (Aravena y Carazo , 2016, p. 29). Tales certificadoras emiten certificaciones para la exportación de productos como la piña, no obstante, al ser reguladas y manejadas por entes privados, el Estado no puede ser garante de cumplimiento de los requisitos legales en el momento de que el producto entra a otro país, ni tampoco garantizar que todos los productores puedan acceder a ellas por sus altos costos, dejando por fuera a muchos pequeños y medianos productores. 
comunicación personal, 13 de julio de 2016).

El desarrollo del nuevo perfil agroexportador de productos no tradicionales, como la piña, generó una destrucción de las condiciones y las dinámicas históricas, económicas, culturales y geográficas propias de la región (León, 2015). La presencia del Estado en el territorio mediante recursos económicos, infraestructura, arreglos espacio-temporales y la creación de instituciones y políticas, le permitieron no solo controlar el territorio y sus dinámicas, sino también la posibilidad de potenciar y consolidar una industria piñera en poco tiempo.

Acuña y Valverde (2011) afirman que estos cantones arrastran la marginalidad propia de todas las zonas fronterizas de Centroamérica. Históricamente, estos cantones han estado ubicados no solo en la línea de frontera desde la perspectiva político administrativa, sino en otra de tipo cultural, que no es tomada en cuenta por parte de estos procesos de ampliación estatal. Además, estas lógicas de acercar e incluir nuevos territorios en el proceso de acumulación de capital, también implica identificar zonas estratégicas para desarrollar las actividades agrícolas. La posición geográfica de la ZN permite la accesibilidad a mucha de mano de obra nicaragüense en la frontera en condición irregular o con vulnerabilidad social y económica (Cortés, 2005).

Por lo tanto, la gran demanda de mano de obra y estacionalidad de los productos agrícolas en el país propician la entrada de muchos inmigrantes irregulares en este sector laboral. Estos flujos de migración son aprovechados y capitalizados en función de los esquemas de monocultivo, así como:

[...] la ausencia de mecanismos legales, la disfunción de los existentes y la falta de capacidad institucional, crean una situación en la cual la producción agrícola de productos como la piña, toma ventaja de la población extranjera que trabaja sin documentos en el país (Lee, 2007, p. 272).

Para Mezzadra y Neilson (2017) la migración no calificada es clave para el encuentro entre capital y el trabajo, la producción legal de la "ilegalidad" en tierras fronterizas crea una gama de posiciones sujetas a las múltiples formas en las que los migrantes pueden estar indocumentados, esto incluye frágiles estatus que pueden adquirir a través de ciertos acuerdos laborales. 
A partir de todo lo analizado hasta acá, es claro cómo los procesos y prácticas estatales llevados a cabo en el territorio ponen evidencia que a lo interno del país se creó una estructura jurídica, económica y de infraestructura propicia para el ingreso del capital foráneo y actores privados (Avendaño et al., 2014). En ese sentido, Costa Rica sufre una serie de transformaciones políticas y económicas que permitieron la entrada de organismos internacionales e inversión extranjera directa que promocionan y responden a un nuevo modelo desarrollo. En este proceso el Estado asume un rol dual dentro de la $\mathrm{ZN}$, es decir, un rol emprendedor en el marco de la producción piñera, y al mismo tiempo un papel pasivo en la monitoreo y regulación de estos procesos.

\section{LAS AUSENCIAS SELECTIVAS DEL ESTADO}

El avance de las políticas neoliberales y ajustes estructurales, que se implementaron en Costa Rica durante y posterior a la década de los ochenta, provocó cambios significativos en la sociedad: minimización del Estado y la maximización del capital en la toma de decisiones relacionadas con las políticas de desarrollo y, por consiguiente, del territorio (Mançano, 2013, p.125). Pero más que una minimización del Estado, se podría hablar de un cambio de prioridades, con menos presencia en el control y con esfuerzo por descentralizar y privatizar procesos (Obando, 2017).

El éxito de la estrategia de inclusión y acercamiento de la $\mathrm{ZN}$ al Valle Central, y la promoción e incentivación por parte del Estado de la industria piñera, puso en evidencia cómo el Estado instrumentalizó el territorio para expresar intereses particulares y relaciones de poder. Efectivamente, el Estado fue quién propició una acelerada expansión, dejándola a cargo de grandes empresas, quienes fueron las beneficiadas del ajuste estructural al modelo productivo costarricense (Obando, 2017).

La intervención estatal en la $\mathrm{ZN}$, se concentró en crear las condiciones necesarias de infraestructura, mano de obra, seguridad jurídica, para que los emprendimientos privados fueran los encargados de controlar y organizar los procesos de producción y la gestión y del espacio. Todo lo anterior, facilitó tanto el ingreso como la expansión de monocultivos, incluyendo el de la piña, ya que le asignó una cuota poder a estas empresas de capital privado para que tuvieran un fuerte impacto en las dinámicas económicas, so- 
ciales y espaciales de la región, en detrimento de los trabajadores agrícolas y las economías campesinas (Obando, 2017).

Durante las diversas entrevistas realizadas a los miembros de las comunidades, se reconoce la contribución económica y el empleo que genera la industria en sus territorios, pero también las implicaciones ambientales y sociales que ha traído consigo. "La única ventaja que se podría decir que trae la piña es el empleo que genera en el cantón" (A2, miembro de la comunidad de Pavón de Los Chiles, comunicación personal, 27 de julio de 2016).

Se supone que el $80 \%$ de la población de acá (de Los Chiles) se beneficia del trabajo de las piñeras, yo no estoy en contra que la gente reciba empleo, pero yo siempre me pregunto ¿A qué precio nos dan de comer? ¿Qué precio estamos pagando? Ok sí, generemos crecimiento económico para el país, pero vamos a quitarle todos los recursos naturales a las zonas productoras (A4, representante indígena Maleku, comunicación personal, 20 de julio de 2016).

Cáceres y Silvetti (2015) plantean que el Estado en diversas ocasiones justifica los emprendimientos extractivos en una determinada región, por medio del discurso de la generación de empleo y desarrollo económico y social que permitirá el "empoderamiento" de las comunidades rurales de su territorio. "Las empresas transnacionales reciben múltiples incentivos por parte del Estado bajo el supuesto de que constituyen la vía rápida para el progreso económico" (p. 3). El agronegocio se nutre, justamente, de esas significaciones productivistas, lo cual en el corto plazo le ayuda a incrementar sus rendimientos, pero a costa de romper la integración entre cultivos, sistemas ecológicos y dinámicas sociales a lo interno de los territorios (Giraldo, 2018, p. 28).

En el caso concreto de los cantones en estudio, los gobiernos locales tratan de evitar el conflicto político y social que implicaría tomar decisiones y medidas concretas, ya que iniciaría un proceso de debate en su territorio (Obando, 2017). Tanto el gobierno - a escala nacional como local- como las empresas, intentan encaminar la discusión por la vía de las soluciones técnicas, donde venden la ilusión que "las buenas prácticas ambientales" resuelven todos los problemas socioambientales (Cáceres y Silvetti, 2015).

Además, existe una tendencia de transferencia de competencias por parte de las Municipalidades a las empresas piñeras y al capital privado en general, ya que no solo brindan empleo a las comunida- 
des, sino que cumplen labores de infraestructura las cuales debería cumplir el gobierno local, como la reparación de caminos vecinales, la recolección de basura, la construcción de escuelas o parques recreativos (Obando, 2017).

Las empresas piñeras generan mano de obra y desarrollo en los pueblos a los que llegan. A veces ellos se encargan de arreglar caminos vecinales por los que su maquinaria pasa o nos donan infraestructura. La verdad nosotros como Municipalidad estamos muy limitados presupuestariamente, entonces eso al final es para la gente (A5, funcionario de Municipalidad de Los Chiles, comunicación personal, 27 de julio de 2016).

En casos como estos, Hibou (2013) argumenta que las empresas se convierten en intermediarios privados que garantizan mayor eficiencia y mejores resultados. Se presentan a diferencia del Estado, menos burocratizados, ya que no necesitan presencia uniforme en todo el territorio y así evitan muchos de los costos del aparato administrativo. No obstante, para Mazzucato (2014), el Estado no es realmente una máquina burocrática e ineficiente, sino que el sector privado en este caso encuentra el "coraje" para invertir, luego de que un Estado "emprendedor" haya hecho las inversiones necesarias y generado el panorama óptimo para su desarrollo. Para el autor, no es necesario caer en la dicotomía de sector público contra sector privado, sino entender la necesidad de que existe un Estado emprendedor previo al desarrollo de capital privado, que sea capaz de asumir riesgos, de actuar como inversor líder y catalizador, no solo como facilitador de la economía y de procesos.

En este contexto, el Estado ha moldeado y creado espacios para que las dinámicas de privatización puedan ejercer su rol, es decir, aplica leyes de forma selectiva, y más bien da pie a que se sigan beneficiando los intereses de empresas capitalistas nacionales y transnacionales (Flint y Taylor, 2002, p.p. 209-210). Al final, las propiedades de las empresas de capital privado están garantizadas, en última instancia, por las leyes de los Estados, en cuyos territorios se asientan sus propiedades. "Todos los Estados necesitan que haya acumulación de capital en su territorio que les proporcione la base material de su poder y todas las empresas de capital privado necesitan las condiciones de acumulación que proporciona el Estado" (Taylor y Flint, 2002, p. 210).

La ausencia selectiva derivada de omisiones, vacíos legales e ins- 
titucionales del Estado costarricense en estos procesos, se puede analizar propiamente en el control, monitoreo y fiscalización de la actividad piñera en la zona de estudio y en el país. A partir de la revisión bibliográfica, la identificación de actores y la realización de diversas entrevistas ${ }^{17}$, se puede destacar varios hallazgos respecto a esa dinámica dual de acción/omisión del Estado costarricense.

Entre una de ellas, es que existe una tendencia por parte del aparato estatal (instituciones públicas tanto nacionales como locales) en promover la expansión piñera por temas de empleo, crecimiento económico y desarrollo. Se tiende a priorizar la generación de divisas de la actividad productiva, en detrimento del bienestar social de las comunidades, lo que afianza una colaboración entre el sector productivo y las instituciones estatales en ambas escalas (Obando, 2017). Se demuestra una falta de información y de coordinación interinstitucional y planificación, ya que no existe una correspondencia entre intervenciones, políticas $\mathrm{u}$ acciones concretas entre escalas (Obando, 2017).

Este es el caso de la Secretaría Técnica Nacional Ambiental (SETENA), los Gobiernos Locales y el Tribunal Ambiental Administrativo. Específicamente, en el caso de SETENA ${ }^{18}$, es la institución encargada de otorgar las viabilidades ambientales ${ }^{19}$ para la opera-

17 Se realizaron un total de 15 entrevistas a actores tanto a escala nacional como local, entre ellos instituciones estatales, empresas y medianos y pequeños productores de piña, así como organizaciones ambientales y comunales de la sociedad civil (Ministerio de Agricultura y Ganadería [MAG], Dirección de Gestión y Calidad Ambiental [DIGECA], Tribunal Ambiental Administrativo, Secretaría Técnica Nacional Ambiental [SETENA], Cámara Nacional de Productores y Exportadores de Piña, CoopePiña, AgroNorte, Centro de Derecho Ambiental y de los Recursos Naturales [CEDARENA], Municipalidades de Guatuso, Los Chiles y Upala, Frente Nacional de Sectores Afectados por la Producción Piñera [FRENASAPP] y organizaciones comunales como Coordinación Lucha Ambiental Norte Norte[CLANN]).

18 La Ley Orgánica de Ambiente, la crea como un órgano de desconcentración máxima del MINAE, cuyo propósito fundamental es entre otros armonizar el impacto ambiental con los procesos productivos, así como el de analizar las evaluaciones de impacto ambiental (EIA) (Asamblea Legislativa de Costa Rica, 1995).

19 La viabilidad ambiental consiste en un estudio que determina tanto los impactos positivos y negativos de nuestro proyecto sobre el medio ambiente y la sociedad, y si los últimos pueden ser compensados o neutralizados en pos del proyecto nacional de desarrollo sostenible (ECOSEG Consultores Ambientales, 2016). Se encuentra regulado en el marco del Reglamento General sobre los Procedimientos de Evaluación de Impacto Ambiental (EIA). 
ción de los proyectos piñeros. Pero la decisión última de la operación o no de un proyecto piñero le compete a las Municipalidades, que deben otorgar la "nota de uso conforme de suelo"20 (Acuña et al., 2018). En teoría, debería establecerse una coordinación entre cada Municipalidad y SETENA, con el fin de establecer un control idóneo y de ubicación de todos los proyectos y obras que se desarrollan en el cantón. Coordinación que ninguno de los actores entrevistados afirmó que existía (Obando, 2017).
SETENA otorga la viabilidad ambiental de los proyectos piñeros en nuestro territorio, pero nosotros, no tenemos ninguna potestad ahí. SETENA no nos envía información. Por ejemplo, las empresas en teoría deberían tener y estar actualizando sus informes de agua, de terrenos cultivados y nosotros como municipalidad deberíamos pedirlos. Lo que pasa, es como no hay una exigencia "desde arriba" o algo que nos respalde no lo hacemos, porque estas empresas tienen su privacidad y ellos dan la información que quieren (A6, funcionario de Municipalidad de Upala, comunicación personal, 13 de julio de 2016).

Las Municipalidades de la zona de estudio hasta el 2017 (fecha en que realizó esta investigación), no contaban con planes reguladores, lo que significa que no tenían un control efectivo sobre el uso del suelo dentro de su territorio. Por tanto, no se sabe que suelos son aptos para la actividad, o cuáles son más vulnerables que otros, porque se tiene un desconocimiento de las potencialidades y limitaciones del territorio (Obando, 2017). Justamente, es acá donde se identifica uno de los problemas principales relacionados a los proyectos piñeros en el país, que están establecidos en zonas donde el gobierno local no tiene los mecanismos formales para regular y administrar el territorio ${ }^{21}$. Así lo afirman algunos de los funciona-

20 Durante este proceso también se debe contar con una con una concesión de pozos otorgado por el Departamento de Aguas del MINAE (DA), a través de la DA, se ejecutan acciones orientadas a gestionar y proteger el recurso hídrico, por medio de los permisos para realizar obras en cauce y descarga de aguas de drenaje agrícola.

21 Incluso, en algunas entrevistas funcionarios de las distintas Municipalidades comentaban que se sometían a importantes presiones y amenazas de parte de las empresas piñeras, para que se les otorgara el permiso de uso de suelo (aunque no contaran con todos los requisitos). En casi todas las ocasiones, la Municipalidad terminaba cediendo debido a la falta de Planes Reguladores que sustentaran técnicamente sus decisiones ante las posibles demandas legales. 
rios Municipales entrevistados.

Nosotros al no tener plan regulador si nos negamos a dar un permiso de uso de suelo, pueden ir y denunciarnos por medio de un recurso de amparo porque estamos impidiendo la "libre producción de productos agrícolas". Nosotros no tenemos el fundamento legal o algo que nos respalde para decirle usted no puede expandirse o este no es el lugar correcto porque no contamos con Plan Regulador o un plan de ordenamiento territorial (A5, funcionario de Municipalidad de Los Chiles, comunicación personal, 27 de julio de 2016).

Con respecto a los mecanismos de fiscalización y seguimiento de los proyectos, SETENA debería controlar y dar seguimiento a todo proyecto aprobado por medio de mecanismos, como el regente ambiental, la bitácora ambiental, el depósito de garantía y los informes de regencia (Obando, 2017). No obstante, se constata serias fallas en el seguimiento y monitoreo de las viabilidades otorgadas, ya que no hay programas de monitoreo bien definidos y los que existen son de carácter reactivo, ante las denuncias de terceros o a solicitud de los mismos desarrolladores (Programa Estado de la Nación, 2016).

Los regentes ambientales al ser contratados por la misma empresa desarrolladora, no pueden garantizar la imparcialidad de los informes de regencia entregados a SETENA (Obando, 2017). Algunas de las empresas que siembran y procesan piña en la $\mathrm{ZN}$ no cuentan con licencias de viabilidad ambiental (Acuña Alvarado y Álvarez, 2019). Además, a partir de las entrevistas realizadas a funcionarios de SETENA, señalan que hay una escasez de recursos y alta carga de trabajo al momento de darle seguimiento y fiscalizar todas las obras y proyectos aprobados. Por lo tanto, la entidad no cuenta con un programa de monitoreo a mediano y largo plazo que permita detectar incumplimientos y abordar problemáticas de seguimiento estratégico (Programa Estado de la Nación, 2016).

Con respecto a los procesos de denuncia y acceso a la justicia, el Departamento de Auditoria y Seguimiento Ambiental de SETENA es el encargado de investigar y resolver las denuncias sobre el incumplimiento de los compromisos ambientales siempre y cuando cuenten con expediente administrativo en SETENA y de no ser así tales denuncias son atendidas por el Tribunal Ambiental Admi- 
nistrativo ${ }^{22}$. Según las entrevistas realizadas, si la obra, actividad o proyecto - en este caso los proyectos piñeros - tiene los permisos necesarios, el Tribunal no entra en el proceso, tampoco le compete fiscalizar si los permisos se dan de la manera adecuada. Únicamente inicia un proceso, cuando se interpone una denuncia formal por algún tipo de afectación en el medio el ambiente.

El proceso del trámite y evaluación de denuncia puede tomar entre 6 meses y hasta 3 años, y en muchas ocasiones debilita el proceso y a las partes implicadas, ya que puede significar que los mecanismos no son ágiles ni eficientes. Asimismo, si se llega algún tipo de resolución, esta puede ser apelable en sede judicial, es decir, no son definitivas ya que puede ser revisada por el Tribunal Contencioso, entonces, no se puede hablar de una sentencia firme, si esta puede ser revisada (Obando, 2017).

A partir de lo expuesto, se demuestra la existencia de instituciones y una legislación para una correcta gestión, monitoreo y fiscalización de las actividades. Sin embargo, se comprueba la falta de recursos, la poca capacidad de control previo, las nulas interrelaciones entre escalas para dar un seguimiento idóneo a las tareas que les competen. A medida en que se expande el monocultivo de piña, no se evidencia un contrapeso institucional por medio de leyes, procesos y políticas que se encargue de regular y fiscalizar dicha actividad productiva (Obando, 2017).

Este doble rol que juega el Estado costarricense, es problemáti$\mathrm{co}$, porque es evidente que sus acciones responden a ciertos intereses de élites y actores privados, pero sus omisiones se generan en detrimento de las comunidades y personas en condiciones de vulnerabilidad que, en este caso, sufren las consecuencias de procesos de producción intensivos y desregulados del cultivo de piña. Así, durante las entrevistas y actividades realizadas con las organizaciones locales y comunidades, eran frecuentes afirmaciones que indicaban: "el Estado no hace nada", "el Estado se hace el ciego y el sordo", "el Estado nos quiere desaparecer", "¿Por qué a veces el Estado aparece y otras veces no?"

22 El Tribunal Ambiental Administrativo fue también creado en 1995 por la Ley Orgánica de Ambiente y empezó a operar en 1997. Según el artículo 103, este Tribunal es un órgano desconcentrado del Ministerio del Ambiente y Energía y tiene competencia exclusiva e independencia funcional y sus resoluciones son de acatamiento estricto, obligatorio y los fallos que agotan la vía administrativa, son irrecurribles (Asamblea Legislativa de Costa Rica 1995). 
Es evidente que la expansión y los problemas derivados del monocultivo de piña no suceden en ausencia del Estado, sino que aquello que se entiende por Estado se manifiesta y se expresa según los intereses que valida y reconoce, los cuales no van en concordancia con los de las comunidades. Es justamente en este punto, donde se puede hablar de esas ausencias selectivas del Estado, porque pese a que juega un rol importante y activo en la promoción de la industria y producción de piña en los territorios. Al mismo tiempo, se encuentra ausente y con un rol difuso y pasivo para aplicar medidas que permitan fiscalizar, regular estos procesos productivos y garantizar los derechos y mecanismos de acceso a la justicia a las comunidades.

\section{CONCLUSIONES: EL ESTADO Y SUS HUELLAS DETRÁS DE LA EXPANSIÓN PIÑERA}

Como se ha expuesto alrededor de todo este artículo no podemos entender al Estado como una entidad unitaria, coherente y neutral ni un actor ajeno a los procesos y prácticas políticas. Como indica Osorio (2014), a pesar de que el Estado se presente como una comunidad de todos y un árbitro, es la única institución que permite que los intereses de los agrupamientos sociales específicos y reducidos puedan ser presentados al resto de la sociedad como intereses de todos. En este sentido, una perspectiva desde la antropología del Estado permite distanciarnos de una concepción que homogeniza la acción estatal, como si fuera una sola fuerza. Más bien, nos brinda herramientas para comprender las múltiples fuerzas que operan en él, las diferencias de poder y complejidades (Hevia de la Jara, 2009).

Eso que se tiene por "Estado", en realidad, no solo se compone de un aparato estatal, sino también de prácticas, procesos, omisiones, acciones y actores a diferentes escalas. El Estado entonces no es una entidad aislada, sino que sus diferentes instituciones y acciones son permeadas e influenciadas por diversos recursos de poder de otros actores, lo que permite que el accionar del Estado en general, le asigne más peso o se incline más a ciertas instituciones, temas o intereses.

Por tal motivo, Jessop (2014) es enfático al decir que una tarea clave del Estado es ayudar a la organización de arreglos espacio temporales que faciliten el aplazamiento y el desplazamiento de 
las contradicciones, las tendencias a la crisis y los conflictos para el beneficio de aquellos completamente incluidos en el interés general, en detrimento de aquellos excluidos de él. Por lo que, si se dan conflictos derivados de los impactos ambientales y sociales de la expansión de piña, es porque el mismo Estado lo permite (Obando, 2017). A través del artículo, se comprobó la existencia de mecanismos públicos de intervención para apuntalar al cambio de un modelo económico y a la re-orientación de la agricultura hacia circuitos, cadenas globales y sistemas agrícolas uniformes, bajo lógicas de monocultivo a gran escala. Al mismo tiempo, se evidenciaron débiles políticas e intervenciones de gestión ambiental, sobre todo lo que respecta a la regulación y fiscalización de los sistemas de producción de piña.

El Estado por medio de diferentes recursos -formales e informales-, así como por sus omisiones, ha estado históricamente presente en el territorio en la promoción de la industria piñera y otros productos no tradicionales, a través de infraestructura, políticas públicas y programas que han afectado de manera directa la configuración de la región. En este contexto, problematizar el rol del Estado permitió constatar cómo (in)opera en la ruralidad, es decir, se mostró esa doble vía de acción/omisión dentro de los territorios.

Esto se debe a que, a pesar de que el Estado se presente de forma unitaria en la búsqueda del desarrollo económico y del bien común, este proceso ha partido desde perspectivas vallecentralistas y desde ciertas élites. Por lo tanto, el Estado costarricense ha tenido una tendencia clara a reproducir mediante la promoción, pero al mismo tiempo bajo la omisión, una lógica hacia la generación de monocultivos y la inversión extranjera, en favor de las grandes empresas. Entonces, las comunidades y los pequeños y medianos productores son los que pierden el acceso a la tierra y sus formas de vida, mientras que los grandes sectores productivos son los ganadores de todas las dinámicas de despojo que impulsa la agroindustria. En este punto, es donde se desliga la supuesta armonía y unidad del Estado, que demuestra el escondimiento de los intereses de las grandes empresas productoras de piña, que dejan sus huellas detrás la "máscara" del Estado (Phillip Abrams, 2015).

Sin embargo, esto también ha permitido visibilizar respuestas políticas de actores subalternos que se han generado dentro de esos procesos estatales. A pesar de que las estructuras de poder del Estado costarricense condicionan la apropiación y producción 
del espacio, también generan la posibilidad de la constitución de contrapoderes sociales, es decir, de resistencias de grupos sociales opuestos a dichas acciones (Obando, 2017).

Por lo tanto, se debe posicionar y reconocer como paulatinamente las comunidades de la $\mathrm{ZN}$ dan sus primeros pasos en construir alguna organización de resistencia en contra de la expansión piñera. El desarrollo de alternativas de resistencia como la producción de cultivos orgánicos para el autoconsumo e intercambio de productos, el turismo rural y la constitución de grupos de mujeres con alternativas productivas son ejemplos desarrollados por las comunidades de Upala, Guatuso y Los Chiles para no depender directamente de la producción piñera y sus empresas (Acuña Alvarado 2019; Obando, 2017).

De la misma manera, cada vez toma cada vez más fuerza la utilización de canales institucionales para hacer valer sus demandas, así como el desarrollo de charlas y foros, la elaboración de material de apoyo para informar, sensibilizando a las comunidades acerca de las consecuencias y problemáticas de la expansión piñera. Sumado a esto, cabe destacar el rol indiscutible de las mujeres en este proceso, las cuales se han apropiado de los espacios de debate y sensibilización, pues son ellas mismas las que han vivido a través de sus cuerpos y cotidianidades los impactos de la producción de piña en sus territorios. De esa manera, son las que han iniciado con el replanteamiento del modelo de producción piñero en sus comunidades (Acuña Alvarado, 2019).

\section{REFERENCIAS}

Abrams, Philip. (1988). Notes on the Difficulty of Studying the State (1977). Journal of Historical Sociology, 1(1), 58-89. https://doi.or$\mathrm{g} / 10.1111 / \mathrm{j} .1467-6443.1988 . t b 00004 . x$

Abrams, P. (2015). Notas sobre la dificultad de estudiar el Estado. En Antropología del Estado (Primera Edición, p. 187). Fondo de Cultura Económica.

Acuña Alvarado, M. (2019). Tierra para las mujeres: Resistencias y procesos organizativos de las Asociaciones de Mujeres de Nueva Esperanza y Caño Negro de Los Chiles (2000-2016). [Tesis de licenciatura, Universidad de Costa Rica]. Repositorio SIBDI UCR http://repositorio.sibdi.ucr. ac.cr:8080/jspui/handle/123456789/9026 
Acuña Alvarado, M., y Álvarez, M. (2019). Situación laboral y ambiental de las piñeras en la Zona Norte. Semanario Universidad. https:// semanariouniversidad.com/opinion/situacion-laboral-y-ambiental-de-las-pineras-en-la-zona-norte/

Acuña, G. (2004). Diagnóstico, situación y condiciones de agroindustria piñera en Costa Rica (p. 64). Asociación de Servicios de Promoción Laboral.

Acuña, G. (2006). Producción de Piña en Caribe y Pacífico Sur de Costa Rica. Ambientico, 158, 20. http://www.ambientico.una.ac.cr/pdfs/ambientico/158.pdf

Acuña, K., y Valverde, J. (2011). Desarrollo local en la Región Huetar Norte Norte. UNED. http://www.uned.ac.cr/extension/images/ifcmdl/ CONTENIDO_2.pdf

Acuña, M., Rodríguez, T., y Obando, A., (2018). Entender el extractivismo en regiones fronterizas. Monocultivos y despojo en las fronteras de Costa Rica. Sociedad y Ambiente, 6(17), 155-200.

Alonso, E. (2013). La propuesta de reforma a la Ley de zonas francas: Retos e implicaciones de política. (Decimoquinto informe Estado de la Nación en Desarrollo Humano Sostenible; p. 21). Estado de la Nación. http:// estadonacion.or.cr/files/biblioteca_virtual/015/Alonso_ZF.pdf

Aravena, J. (2005). La expansión piñera en Costa Rica. La realidad de los perdedores de la agroindustria exportadora de la piña. (p. 56). Asociación Comunidades Ecologistas la Ceiba. http://coecoceiba.org/wp-content/ subidas/2010/03/pub11.pdf

Arias, J. (2016). La antropología del estado desde Akhil Gupta: A propósito de Red Tape: Burocracia, violencia estructural y pobreza en India. Universitas humanística, 82, 463-473.

Asamblea Legislativa de Costa Rica. (1995). Ley Orgánica del Ambiente $\left(N^{\circ} 7554\right)$. http://www.inbio.ac.cr/estrategia/Leyes/Ley_Ambien. html

Avendaño, K. R., Ramírez, K. P., y Segura, A. G. (2014). “Más allá del trabajo asalariado: Implicaciones sociales en el uso del tiempo no remunerado de trabajadoras y trabajadores vinculados al monocultivo de piña en la comunidad de Pital de San Carlos en los años 2012-2013". Univesidad de Costa Rica.

Barragán, R., y Wanderley, F. (2009). Etnografías del Estado en América Latina. Íconos, 34, 21-25.

Barrientos, O., y Chaves, G. (2008). Región Huetar Norte: Oferta exportada actual y potencial de productos agropecuarios alternativos.

Berrocal, J., Pratt, L., y Quijandría, G. (1997). Industria de piña en Costa Rica: 
Análisis de sostenibilidad (p. 27). INCAE Business School. http://www. incae.edu/ES/clacds/publicaciones/articulos/cen707.php

Cabrol, D., Cáceres, D., Silvetti, F. y Soto, G. (2013). ¿Por qué la legislación no protege los bosques nativos de Argentina? Conflictos socioambientales y políticas públicas. Mundo Agrario, 13.

Cáceres, D. y Silvetti, F. (2015). La expansión de monocultivos de exportación en Argentina y Costa Rica. Conflictos socioambientales y lucha campesina por la justicia ambiental. Mundo Agrario, 16. http:// www.mundoagrario.unlp.edu.ar/files/journals/1/articles/5313/public/5313-11891-1-PB.pdf

Carazo, E., y Aravena, J. (2016). Condiciones de producción, impactos humanos y ambientales en el sector piña en Costa Rica. Asociación Regional Centroamericana para el Agua y el Ambiente.

Castillo, O. G. (2006). Apertura Económica, políticas agrícolas y campesinado entre tres sistemas agrarios de la Región Huetar Notre, Costa Rica [Magister Scientiae]. Univesidad de Costa Rica.

Castro, S., y Cuadrado, G. (2010). La expansión del monocultivo de piña en detrimento de los derechos humanos. (R. Rodríguez, Trad.). FIAN Internacional, FIAN Suecia, HIC-AL, SAL. http://www.hic-al.org/noticias.cfm?noticia $=856 \&$ id_categoria $=8$

Cortés, A. (2005). Reflexiones sobre la dinámica migratoria entre Nicaragua y Costa Rica en los 90's.

ECOSEG Consultores Ambientales. (2016). La Viabilidad Ambiental de SETENA. https://ecoseg.org/2016/05/07/viabilidad-ambiental-setena/

Flint, C. y Taylor, P. (2002). Geografía Política: Economía mundo, Estado-Nación y Localidad. (2 edición.). Trama Editorial.

Giraldo, O. F. (2018). La ecología política de la agricultura. Agroecología y posdesarrollo. El Colegio de la Frontera Sur.

Granados, C., y Quesada, L. (1986). Los intereses geopolíticos y el desarrollo de la zona nor-atlántica costarricense. Estudios Sociales Centroamericanos, 47-55.

Gudynas, E. (2009). Diez tesis urgentes sobre el nuevo extractivismo. En Extractivismo, Política y Sociedad (pp. 187-223). CLACSO. http:/ /www. redge.org.pe/extractivismo-politica-sociedad

Gudynas, E. (2013). Extracciones, extractivismos y extrahecciones. Un marco conceptual sobre la apropiación de recursos naturales. 18, 1-18. http:// www.academia.edu/4242453/Extracciones_extractivismos_y_extrahecciones._Un_marco_conceptual_sobre_la_apropiaci\%C3\%B3n_de_ 
recursos_naturales

Hernández, A., Obando, A., y Schuster, D. (2015). Conflicto de la moratoria piñera en los cantones de Pococí, Guácimo y Siquirres.

Hevia de la Jara, F. (2009). Relaciones sociedad-Estado: Análisis interactivo para una antropología del Estado. Espiral (Guadalajara), 15(45), 43-70. http://www.scielo.org.mx/scielo.php?script=sci_abstract\&pi$\mathrm{d}=$ S1665-05652009000300002\&lng=es\&nrm=iso\&tlng=es

Hibou, B. (2013). De la privatización de las economías a la privatización de los Estados. Fondo de Cultura Económica.

Jessop, B. (2014). El Estado y poder. Utopia y Praxis Latinoamericana, 19, 19-35.

Jiménez, A., Porras, M. y Valverde, K. (2016). La expansión por omisión: Territorios piñeros en los cantones de Upala, Los Chiles y Guatuso (20042005). Programa Estado de la Nación.

Lee, S. (2007). Trabajadoras inmigrantes y exportaciones agrícolas no tradicionales: Trabajadoras en plantas empacadoras en Costa Rica. En C. Sandoval (Ed.), El mito roto: Inmigración y emigración en Costa Rica (Instituto de Investigaciones Sociales, pp. 253-292). Universidad de Costa Rica.

León, A. (2015). Desarrollo geográfico desigual en Costa Rica: El ajuste estructural visto desde la Región Huetar Norte (1985-2005). (1 edición). UCR.

Llaguno, J. J. L., Mora Solano, S., Gutiérrez Espeleta, A. L., Barrios Alfaro, P., y Mora Moraga, F. (2014). Políticas y conflictos socioambientales: El caso de la tenencia de la tierra y los monocultivos en el Caribe de Costa Rica (2006-2012). Revista de Ciencias Sociales, 145. https://doi. org/10.15517/rcs.v0i145.17612

Maglianesi, M. A. (2013). Desarrollo de las piñeras en Costa Rica y sus impactos sobre ecosistemas naturales y agro-urbanos. Biocenosis, 27, 62-70. https: / /cutt.ly/JgVtI1n

Mançano, B. (2013). Territorios: Teoría y disputas por el desarrollo rural. Novedades en Población, 116-133.

Martínez Valle, L. (2012). Apuntes para pensar el territorio desde una dimensión social. Ciências Sociais Unisinos, 48, 12-18.

Mazzucato, M. (2014). The Entrepreneutral State. Debunking public vs. Private Sector Myths. Anthem Press.

Mezzadra, S., y Neilson, B. (2017). La frontera como método. Traficantes de sueños. https://www.traficantes.net/libros/la-frontera-como-m\%C3\%A9todo 
Monzote, R. F. (2013). El Gran Caribe. De las plantaciones al turismo. RCC Perspectives, 7, 17-24. JSTOR. https://www.jstor.org/stable/26241163

Obando, A. (2017). El Estado detrás de la piña: El conflicto socioambiental del monocultivo de piña los cantones de Upala, Guatuso y Los Chiles (2000-2015). ). [Tesis de licenciatura, Universidad de Costa Rica]. Repositorio Kerwá http://www.kerwa.ucr.ac.cr:8080/bitstream/ handle/10669/80895/Tesis\%20Licenciatura\%20Alexa\%20Obando. pdf? sequence $=1 \&$ is Allowed $=\mathrm{y}$

Ohlsson, A. (1985). La Evolución de los lugares centrales en la Región Norte de Costa Rica.

Osorio, J. (2014). El Estado en el centro de la mundialización (Segunda Edición). Fondo de Cultura Económica.

Programa Estado de la Nación. (2014). Vigésimo Informe del Estado de la Nación en Desarrollo Humano Sostenible (XX Informe-Estado de la Nación 2014). Programa del Estado de la Nación. http:/ / www.estadonacion. or.cr $/ 20$ /

Programa Estado de la Nación. (2016). Vigesimosegundo Informe Estado de la Nación en Desarrollo Humano Sostenible (No 22).

Promotora de Comercio Exterior. (2015). Estadísticas de Comercio Exterior de Costa Rica (p. 242). Promotora de Comercio Exterior de Costa Rica. http://www.procomer.com/uploads/downloads/anuario-estadistico-2014.pdf

Prunier, D. y Rodríguez Echavarría, T. (2020). Extractivismo agrícola, frontera y fuerza de trabajo migrante: La expansión del monocultivo de piña en Costa Rica. Frontera Norte: revista internacional de fronteras, territorios y regiones, 32, 1-25.

Rodríguez, T. (2008). Vecinos entre fronteras: Experiencia de las comisiones transfronterizas locales del Proyecto Alianzas de la UICN como plataformas de cooperación y gobernanza ambiental descentralizada 2004-2008. Unión Internacional para la Conservación de la Naturaleza.

Sáenz, M., y Sánchez, J. (2008). Diagnóstico: Tendencias laborales, socioeconómicas y ambientales del monocultivo de banano y piña, en los últimos cinco años en el Caribe costarricense. (p. 100). Foro Emaús.

Schavelzon, S. (2010). La antropología del Estado, su lugar y algunas de sus problemáticas. PUBLICAR, IX, 73-96.

Stonich, S., y De Walt, B. (2006). The political ecology of Deforestation in Honduras. En The Environment in Anthropology: A reader in Ecology, Culture, and Sustainable Living (pp. 284-301). New York University 
Press.

Trouillot, M. (2001). The Anthropology of the State in the Age of Globalization: Close Encounters of the Deceptive Kind. Current Anthropology, 42(1), 125-138. JSTOR. https://doi.org/10.1086/318437

Vallejo Cerna, A. (2014). Productos estrella en Centroamérica entre imaginarios, exportaciones y mitos. Un análisis cuantitativo y comparativo del banano y el cafe en Honduras y Costa Rica: 1970-1976. Paradigma: Revista de Investigación Educativa, 71-80.

Wolf, E. (1982). Europe and the People without history. University of California Press.

ALEXA OBANDO CAMPOS es costarricense. Licenciada en Ciencias Políticas por la Universidad de Costa Rica. Estudiante egresada de la Maestría en Investigación en Estudios Socioambientales, Facultad Latinoamericana de Ciencias Sociales (FLACSO), Sede Ecuador. 